\title{
Protective effect of avicularin on rheumatoid arthritis and its associated mechanisms
}

\author{
WEI WANG, HONGXIA ZHENG, MINWEI ZHENG, XIAOXIAN LIU and JIANNING YU
}

Department of Rheumatology and Nephrology, Hangzhou Red Cross Hospital, Hangzhou, Zhejiang 310003, P.R. China

Received May 17, 2018; Accepted August 31, 2018

DOI: $10.3892 /$ etm.2018.6872

\begin{abstract}
The present study aimed to investigate the effect of avicularin on rheumatoid arthritis (RA) in vitro, and additionally explore the molecular mechanism. To perform this investigation, an in vitro model of RA was established by treatment of the human RA synovial MH7A cell line with tumor necrosis factor- $\alpha$ (TNF- $\alpha)$. MH7A cells were then treated with various concentrations $(10,30,100$ and $300 \mu \mathrm{M})$ of avicularin. Then, the levels of inflammatory factors [interleukin (IL)-1 $\beta$, IL-6, IL-8, matrix metalloproteinase (MMP)-1 and MMP-13] were measured by ELISA. Cell viability and apoptosis were detected using an MTT assay and flow cytometry, respectively. In addition, the expression levels of genes and proteins were determined reverse transcription quantitative polymerase chain reaction and western blot analysis. The results of the present study indicated that avicularin significantly decreased the levels of inflammatory factors (IL-1 $\beta$, IL-6, IL-8, MMP-1 and MMP-13), previously increased by TNF- $\alpha$, in a dose-dependent manner. Concurrently, avicularin inhibited the mRNA and protein expression levels of iNOS and COX-2 increased by TNF- $\alpha$. It was also identified that TNF- $\alpha$ administration significantly promoted MH7A cell viability and inhibited cell apoptosis, and avicularin treatment dose-dependently inhibited MH7A cell viability and induced cell apoptosis. In addition, these data suggested that avicularin prevented the activation of the mitogen-activated protein kinase kinase (MEK)/nuclear factor kappa light-chain-enhancer of activated B-cells $(\mathrm{NF}-\kappa \mathrm{B})$ pathway activated by TNF- $\alpha$. Taken together, these results demonstrated that avicularin may inhibit the inflammatory response, prevent cell viability and induce apoptosis in human RA synovial cells through preventing the activation of the $\mathrm{MEK} / \mathrm{NF}-\kappa \mathrm{B}$ pathway.
\end{abstract}

Correspondence to: Dr Jianning Yu, Department of Rheumatology and Nephrology, Hangzhou Red Cross Hospital, 208 Huanchengdong Road, Hangzhou, Zhejiang 310003, P.R. China

E-mail: yujn2018@163.com

Key words: rheumatoid arthritis, avicularin, synovial fibroblasts, inflammatory response

\section{Introduction}

Rheumatoid arthritis (RA) is a common chronic autoimmune inflammatory disease of unknown etiology that affects $1 \%$ of the global population (1-3). In China, the prevalence of $\mathrm{RA}$ is $0.24-0.50 \%$, and RA is more common among women compared with men (4). The primary features of rheumatoid arthritis are joint swelling, joint stiffness and deformity, and cartilage destruction $(5,6)$. At present, the pathogenesis of RA has not been fully elucidated, but it is generally accepted that RA is caused by the interaction of genetic, immune and environmental factors (7). The current treatment of RA is primarily invasive anti-rheumatic therapy in the early stages of the disease. In order to avoid potential adverse reactions caused by second-line drugs, non-invasive and highly specific diagnostic and therapeutic methods are necessary.

Synovial fibroblasts (SFs), also known as fibroblast-like synoviocytes, have been demonstrated to serve an important role in the pathogenesis of RA, and their tumor-like proliferation leads to the development of synovial hyperplasia $(8,9)$. During RA, activated SFs accumulate in the hyperplastic synovium of patients with RA. Increased levels of inflammatory cytokines, chemokines and matrix metalloproteinases (MMPs) mediate inflammation and cartilage degradation, eventually leading to joint destruction (9). At present, basic in vitro experiments using RA SFs have been performed to examine the pathogenesis of $\mathrm{RA}$, in order to provide a theoretical basis for the exploration of RA ideal treatment methods (10-12). At present, although great progress has been made in the therapeutic strategy of RA, the efficacy remains unsatisfactory. Therefore, novel treatment therapies for RA are urgently required.

Avicularin, quercetin- $3-\alpha$-L-arabinofuranoside, is a bio-active flavonol that may be isolated from a number of plants. Flavonoids have been previously suggested to exhibit various biological properties, including hepatoprotective, anti-oxidative, anti-allergic, anti-tumor and anti-inflammatory activities (13-18). Quercetin (19,20) and other flavonoids (21) have also been demonstrated to serve a role in RA. Avicularin is a glycoside of quercetin, and quercetin is lipophilic while avicularin is hydrophilic, and they may differ in absorption rates (22). Although the biological activities of quercetin, an aglycone of avicularin, have been extensively examined, the biological properties of avicularin itself have not been fully studied. A recent study revealed that avicularin may reverse 
multidrug resistance in human gastric cancer by increasing the expression levels of B-cell lymphoma 2 (Bcl-2)-associated $\mathrm{X}$ protein (Bax) and BOK (16). Vo et al (17) suggested that avicularin serves an anti-inflammatory role by inhibiting the extracellular signal-related kinase signaling pathway in lipopolysaccharide-stimulated RAW 264.7 macrophages. Fujimori and Shibano (18) indicated that avicularin may suppresses lipid accumulation in mouse adipocytic 3T3-L1 cells. These data indicated that avicularin has a specific regulatory effect in cell growth and the inflammatory response, suggesting that it may have a certain effect on RA development by regulating the growth and inflammatory response of RA SFs. However, to the best of our knowledge, no study has been conducted investigating the effects of avicularin in RA.

The aim of the present study was to investigate the effect and the underlying molecular mechanisms of avicularin in RA treatment in vitro. The in vitro model of RA was established by treatment of the human rheumatoid arthritis fibroblast-like synoviocytes MH7A cell line with tumor necrosis factor- $\alpha$ (TNF- $\alpha$ ), a well-recognized cell model that is widely used in in vitro studies of RA (23-25). The current study demonstrated that avicularin inhibited the inflammatory response and cell viability, and induced apoptosis in TNF- $\alpha$-treated human RA synovial cells through preventing the activation of the mitogen-activated protein kinase kinase/nuclear factor kappa light-chain-enhancer of activated B-cells pathway.

\section{Materials and methods}

Cell culture. The human RA synovial MH7A cell line was obtained from Shanghai Guandao Biological Engineering Co., Ltd. (Shanghai, China; cat no. C0878). Cells were grown in RPMI-1640 medium (Hyclone; GE Healthcare Life Sciences, Logan, UT, USA) containing 10\% fetal bovine serum (Gibco; Thermo Fisher Scientific, Inc., Waltham, MA, USA) and $1 \%$ penicillin-streptomycin solution (Sigma-Aldrich; Merck $\mathrm{KGaA}$, Darmstadt, Germany), and incubated at $37^{\circ} \mathrm{C}$ with $5 \% \mathrm{CO}_{2}$.

Cell treatment. MH7A cells were pre-treated with various concentrations of avicularin $(10,30,100$ and $300 \mu \mathrm{M})$ for $2 \mathrm{~h}$, then the cells were subjected to treatment with TNF- $\alpha$ (10 ng/ml; Sigma-Aldrich; Merck KGaA) at room temperature for $24 \mathrm{~h}$ to establish the in vitro model of RA. Cells in the control group were treated with normal RPMI-1640 medium.

MTT assay. An MTT assay was used to detect cell viability. The MH7A cells were seeded into each well $\left(5 \times 10^{5}\right.$ cells per well) and incubated with various concentrations of avicularin $(10,30,100$ and $300 \mu \mathrm{M})$ for $24 \mathrm{~h}$ at $37^{\circ} \mathrm{C}$. Then, $0.5 \mathrm{mg} / \mathrm{ml}$ MTT (in PBS) was added to every well, and the cells were incubated for an additional $3 \mathrm{~h}$ at $37^{\circ} \mathrm{C}$ with $5 \% \mathrm{CO}_{2}$. Dimethyl sulfoxide was used to dissolve the formazan crystals. Finally, absorbance was detected at $590 \mathrm{~nm}$ using a microplate reader (Bio-Rad Laboratories, Inc., Hercules, CA, USA).

Cell apoptosis assay. MH7A cells were treated with 10, 30,100 or $300 \mu \mathrm{M}$ avicularin and $10 \mathrm{ng} / \mathrm{ml} \mathrm{TNF}-\alpha$. Then, MH7A cell apoptosis was analyzed using an Annexin V-fluorescein isothiocyanate (FITC) apoptosis detection kit [cat no. 70-AP101-100; Hangzhou MultiSciences (Lianke) Biotech, Co., Ltd., Hangzhou, China]. Briefly, MH7A cells (5x10 ${ }^{5}$ cells per well) were dyed with Annexin V-FITC and propidium iodide according to the manufacturer's protocol. Flow cytometry (BD Biosciences, Franklin Lakes, NJ, USA) was performed to analyze cell apoptosis, and data were analyzed using Version 2.5 WinMDI (Purdue University Cytometry Laboratories; http://www.cyto.purdue.edu/flowcyt/ software/Catalog.html) software.

ELISA. To detect the production of interleukin (IL) $-1 \beta$ (cat. no. Ab100562), IL-6 (cat no. Ab46027), IL-8 (cat. no. Ab46032), MMP-1 (cat no. Ab100603) and MMP-13 (cat. no. Ab100605), the MH7A cell culture medium was collected by centrifugation at $4^{\circ} \mathrm{C}$ and $1,048 \mathrm{x}$ g for $10 \mathrm{~min}$. ELISAs were performed according to the manufacturer's protocol of each ELISA kit (all Abcam, Cambridge, UK).

\section{Reverse transcription quantitative polymerase chain reaction} $(R T-q P C R)$. Total RNA from MH7A cells was isolated using TRIzol $^{\circledR}$ reagent (Thermo Fisher Scientific, Inc.) according to the manufacturer's protocol. cDNA was generated using the PrimeScript $^{\mathrm{TM}}$ RT reagent kit (Takara Bio, Inc., Otsu, Japan) following the manufacturer's protocol. qPCR was performed by using the SYBR ${ }^{\circledR}$ Premix Ex Taq ${ }^{\mathrm{TM}}$ II (Takara Bio Inc.). Amplification conditions were as following: $95^{\circ} \mathrm{C}$ for $10 \mathrm{~min}$, followed by 37 cycles at $95^{\circ} \mathrm{C}$ for $15 \mathrm{sec}$ and $72^{\circ} \mathrm{C}$ for $30 \mathrm{sec}$ and $78^{\circ} \mathrm{C}$ for $1.5 \mathrm{~min}$, following which samples were stored at $4^{\circ} \mathrm{C}$. GAPDH was used as an internal control. Primers are stated in Table I. Relative gene expression was analyzed by performing the $2^{-\Delta \Delta \mathrm{Cq}}$ method (26).

Western blot analysis. MH7A cells were treated with 10, 30, 100 or $300 \mu \mathrm{M}$ avicularin and $10 \mathrm{ng} / \mathrm{ml}$ TNF- $\alpha$. Then, total proteins from MH7A cells were isolated using radioimmunoprecipitation assay lysis buffer (Beijing Solarbio Science and Technology Co., Ltd., Beijing, China). The quantification of the proteins was measured by BCA assay (Thermo Fisher Scientific, Inc.) following the manufacturer's protocol. Equal amounts of protein samples $(25 \mu \mathrm{g} /$ lane $)$ were separated on $12 \%$ SDS-PAGE and then transferred to polyvinylidene fluoride membranes. The membranes were firstly blocked with 5\% non-fat milk in PBS with $0.1 \%$ Tween-20 for $2 \mathrm{~h}$ at room temperature, and then incubated with primary antibodies (all Cell Signaling Technology, Inc., Danvers, MA, USA) against phosphorylated mitogen-activated protein kinase kinase 1/2 (p-Mek1/2; cat. no. 2338), p-transcription factor p65 (p-p65; cat. no. 3033), inducible nitric oxide synthase (iNOS; cat. no. 13120), cyclooxygenase 2 (COX-2; cat. no. 12282), Bcl-2 (cat. no. 4223), Bax (cat. no. 5023; all dilution, 1:1,000) or $\beta$-actin (cat. no. 4970; dilution, 1:2,000) at $4^{\circ} \mathrm{C}$ overnight. Subsequently, the membranes were incubated with the horseradish peroxidase-conjugated anti-rabbit IgG secondary antibody (cat. no. 7074; dilution, 1:5,000; Cell Signaling Technology, Inc.) for $2 \mathrm{~h}$ at room temperature. Finally, a chemiluminescence detection kit (Cell Signaling Technology, Inc.) was used to visualize the blots according to the manufacturer's protocol. Gel-Pro Analyzer densitometry software (version 6.3; Media Cybernetics, Inc., Rockville, MD, USA) was used for band density quantification. 
Table I. Primer sequences of reverse transcription quantitative polymerase chain reaction.

Primer (5'-3')

Gene

Forward

Reverse

Inducible nitric oxide synthase

Cyclooxygenase 2

B-cell lymphoma 2

Bcl-2-associated $\mathrm{X}$ protein

GAPDH

GAGAAGTCCAGCCGCACCAC
TCCATTGACCAGAGCAGAGA
TTGGATCAGGGAGTTGGAAG
CGTCCACCAAGAAGCTGAGCG
CTTTGGTATCGTGGAAGGACTC

GAACAATCCACAACTCGCCCAAG

TCTGGACGAGGTTTTTCCAC

TGTCCCTACCAACCAGAAGG

TGTCCCTACCAACCAGAAGG GTAGAGGCAGGGATGATGTTCT

Bcl-2, B-cell lymphoma 2.
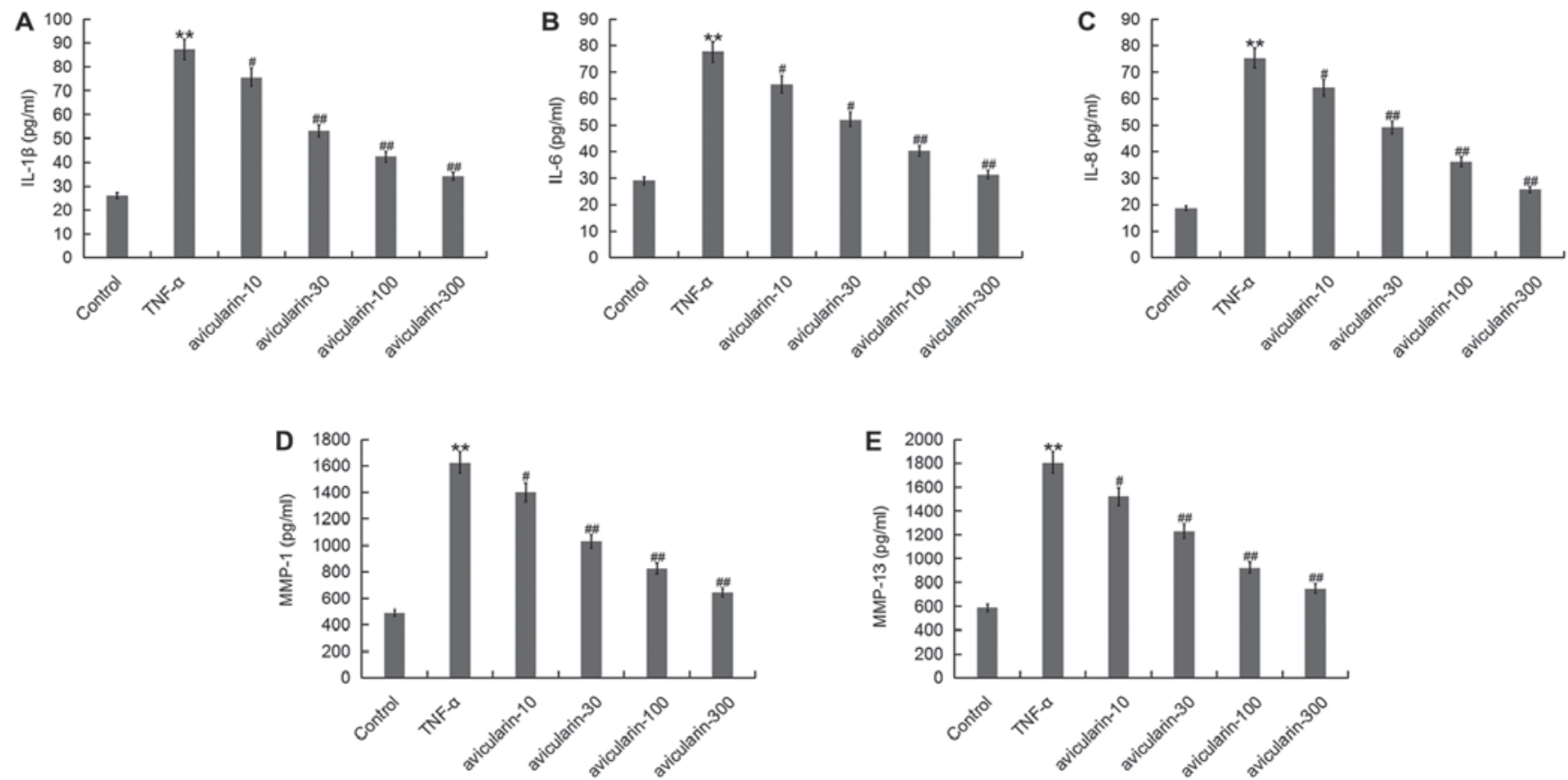

Figure 1. Effect of avicularin on the production of inflammatory factors. MH7A cells were pre-treated with various concentrations of avicularin (10, 30, 100 and $300 \mu \mathrm{M}$ ) for $2 \mathrm{~h}$, then the cells were subjected to treatment with $10 \mathrm{ng} / \mathrm{ml}$ TNF- $\alpha$ at room temperature for $24 \mathrm{~h}$. The levels of inflammatory factors including (A) IL-1 $\beta$, (B) IL-6, (C) IL-8, (D) MMP-1 and (E) MMP-13 were detected by ELISA. Data are expressed as the mean \pm standard deviation. ** P<0.01 vs. control group; ${ }^{~} \mathrm{P}<0.05$ and ${ }^{\# /} \mathrm{P}<0.01$ vs. TNF- $\alpha$ treatment-alone group. IL, interleukin; MMP, matrix metalloproteinase; TNF- $\alpha$, tumor necrosis factor $\alpha$.

Statistical analysis. Data are presented as the mean \pm standard deviation. SPSS 16.0 statistical software (SPSS, Inc., Chicago, IL, USA) was used for all statistical analyses. The associations between two groups were analyzed by a paired Student's t-test, and the comparisons among more than two groups were performed using a one-way analysis of variance followed by a Student-Newman-Keuls post-hoc test. $\mathrm{P}<0.05$ was considered to indicate a statistically significant difference.

\section{Results}

Avicularin inhibits the production of inflammatory factors increased by TNF- $\alpha$. The effect of avicularin on the inflammatory response in the human RA synovial MH7A cell line was first investigated. As demonstrated in Fig. 1, the expression of inflammatory factors, including IL-1 $\beta$, IL-6, IL-8, MMP-1 and MMP-13 were significantly increased by TNF- $\alpha$ treatment. However, compared with the TNF- $\alpha$-alone treatment group, avicularin significantly decreased the level of IL-1 $\beta$, IL-6, IL-8, MMP-1 and MMP-13 in MH7A cells in a dose-dependent manner.

Avicularin inhibits the expression of iNOS and COX-2 increased by $T N F-\alpha$. Then, the effect of avicularin treatment on iNOS and COX-2 expression was examined using RT-qPCR and western blot analysis. The results indicated that avicularin administration dose-dependently inhibited the protein (Fig. 2A) and mRNA (Fig. 2B and C) expression of iNOS and COX-2, which were increased by TNF- $\alpha$ treatment in MH7A cells (Fig. 2).

Avicularin inhibits the TNF- $\alpha$-dependent increase in $M H 7 A$ cell viability. To examine whether avicularin affected the cell viability of MH7A cells, an MTT assay was performed. 
A

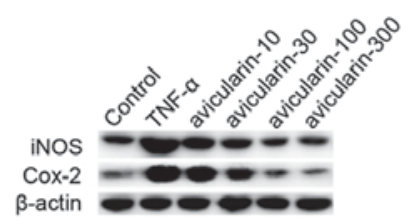

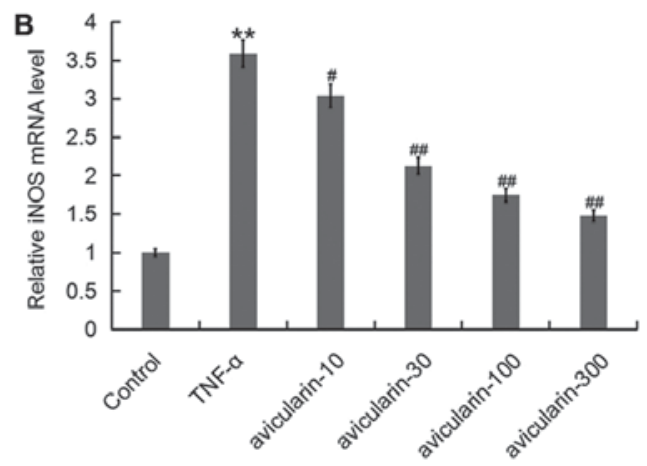

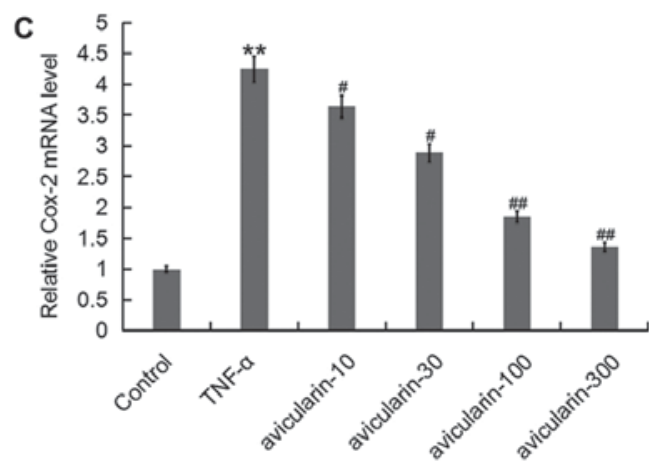

Figure 2. Effect of avicularin on the expression of iNOS and COX-2 in MH7A cells. MH7A cells were pre-treated with various concentrations of avicularin $(10,30,100$ and $300 \mu \mathrm{M})$ for $2 \mathrm{~h}$, then the cells were subjected to treatment with $10 \mathrm{ng} / \mathrm{ml} \mathrm{TNF}-\alpha$ at room temperature for $24 \mathrm{~h}$. (A) The protein levels of iNOS and COX-2 were determined by western blot analysis. The mRNA levels of (B) iNOS and (C) COX-2 were determined by reverse transcription quantitative polymerase chain reaction. Data are expressed as the mean \pm standard deviation. ${ }^{* *} \mathrm{P}<0.01$ vs. control group; ${ }^{*} \mathrm{P}<0.05$ and ${ }^{\# \#} \mathrm{P}<0.01$ vs. TNF- $\alpha$ treatment-alone group. iNOS, inducible nitric oxide synthase; COX-2, cyclooxygenase 2; TNF- $\alpha$, tumor necrosis factor $\alpha$.

It was identified that TNF- $\alpha$ treatment significantly increased the cell viability of MH7A cells, while avicularin dose-dependently prevented the cell viability of MH7A cells (Fig. 3).

Avicularin induces MH7A cell apoptosis inhibited by TNF- $\alpha$. To investigate the effect of avicularin on MH7A cell apoptosis, flow cytometry was performed. As indicated in Fig. 4A and B, compared with the control group, the number of apoptotic cells in the TNF- $\alpha$ treatment group was significantly decreased, and avicularin dose-dependently induced MH7A cell apoptosis. Concomitantly, the expression levels of apoptosis-associated proteins $\mathrm{Bcl}-2$ and $\mathrm{Bax}$ were measured. The results suggested that TNF- $\alpha$ treatment significantly increased Bcl-2 expression and inhibited Bax expression in MH7A cells. Compared with the TNF- $\alpha$-alone treatment group, the level of Bcl-2 was notably decreased and Bax was increased by avicularin treatment in a dose-dependent manner (Fig. 4C-E).

Avicularin prevents the activation of the MEK/nuclear factor kappa light-chain-enhancer of activated B-cells $(N F-\kappa B)$ pathway activated by TNF- $\alpha$. Finally, to explore the molecular mechanism of the effect of avicularin treatment on MH7A cells, the MEK/NF- $\kappa \mathrm{B}$ pathway was analyzed. As hypothesized, it was identified that TNF- $\alpha$ significantly increased the protein levels of $p-M E K / 1 / 2$ and $p-p 65$, and avicularin treatment dose-dependently decreased the protein expression levels of p-MEK/1/2 and p-p65 (Fig. 5).

\section{Discussion}

In the present study, it was demonstrated that avicularin inhibited the production of inflammatory factors enhanced by TNF- $\alpha$ treatment. The results also indicated that TNF- $\alpha$ administration significantly promoted MH7A cell viability and inhibited cell apoptosis, and avicularin treatment dose-dependently inhibited MH7A cell viability and induced cell apoptosis through repressing the MEK/NF- $\mathrm{KB}$ pathway. It was revealed that avicularin may be a promising therapeutic agent for the treatment of RA.

RA is a systemic autoimmune disease characterized by chronic inflammation, synovial hyperplasia, and bone and

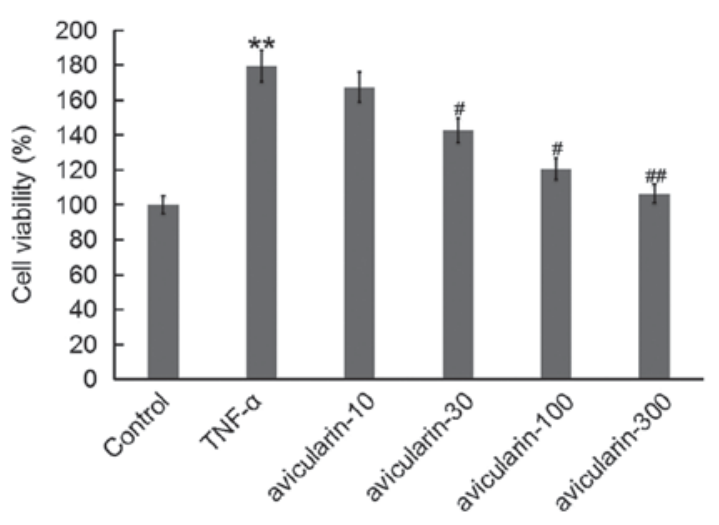

Figure 3. Effect of avicularin on MH7A cell viability. MH7A cells were pre-treated with various concentrations of avicularin $(10,30,100$ and $300 \mu \mathrm{M})$ for $2 \mathrm{~h}$, then the cells were subjected to treatment with $10 \mathrm{ng} / \mathrm{ml} \mathrm{TNF}-\alpha$ at room temperature for $24 \mathrm{~h}$. Cell viability was assessed by MTT assay. Data are expressed as the mean \pm standard deviation. ${ }^{* *} \mathrm{P}<0.01$ vs. control group; ${ }^{\#} \mathrm{P}<0.05$ and ${ }^{\# \#} \mathrm{P}<0.01$ vs. TNF- $\alpha$ treatment-alone group. TNF- $\alpha$, tumor necrosis factor $\alpha$.

cartilage destruction as the primary pathological symptoms $(27,28)$. At present, there is no drug that may completely controls the condition of RA, and prevents bone destruction and erosion; a method of specifically and successfully treating RA has not yet been identified. The treatment and successful cure of RA remains a challenge to the global medical community, and requires additional study.

Avicularin, a bioactive flavonol isolated from a large number of plants, has been identified to exhibit a variety of pharmacological properties, including anti-inflammatory effects $(16,17)$. Avicularin serves an important role in regulating the inflammatory response and cell growth. Avicularin is a glycoside of quercetin, and quercetin has been suggested to serve a protective role in RA $(19,20)$; however, the effect of avicularin on RA remains unknown. A large number of studies have indicated that SFs are the primary cells of synovial hyperplasia and that they serve a key role in the pathogenesis of RA synovium (9-12). SFs participate in the entire process of inflammation and angiogenesis, eventually causing invasive destruction of bone joints $(29,30)$. At present, to the best of our knowledge, the specific effect and 


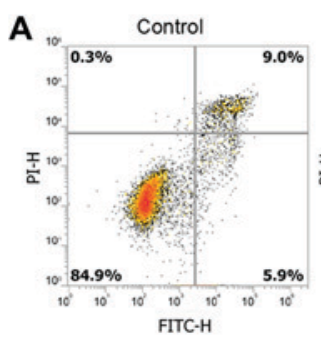

B

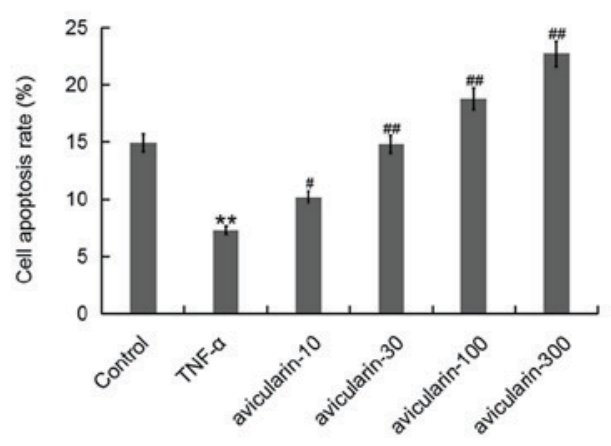

D

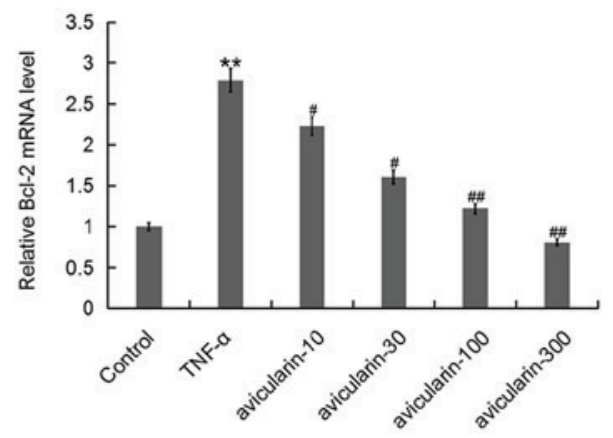

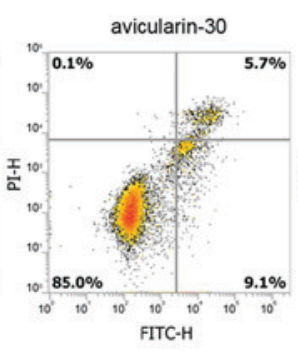
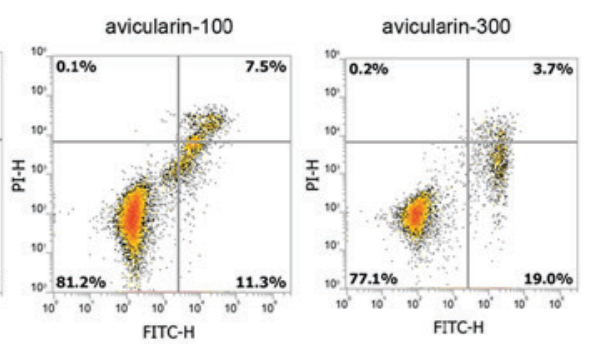

C
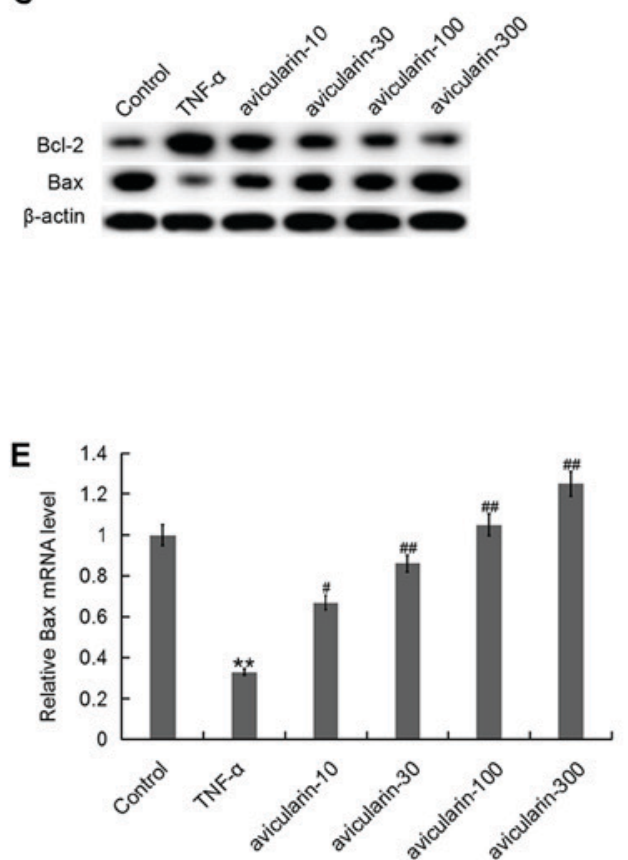

Figure 4. Effect of avicularin on MH7A cell apoptosis. MH7A cells were pre-treated with various concentrations of avicularin (10, 30, 100 and $300 \mu \mathrm{M})$ for $2 \mathrm{~h}$, then the cells were subjected to treatment with $10 \mathrm{ng} / \mathrm{ml} \mathrm{TNF}-\alpha$ at room temperature for $24 \mathrm{~h}$. (A) Flow cytometry was used to detect cell apoptosis. (B) The data was analyzed. (C) The protein levels of Bcl-2 and Bax were measured using western blot analysis. The mRNA levels of (D) Bcl-2 and (E) Bax were measured using reverse transcription quantitative polymerase chain reaction. Data are expressed as the mean \pm standard deviation. ${ }^{* *} \mathrm{P}<0.01$ vs. control group; ${ }^{\#} \mathrm{P}<0.05$ and ${ }^{\# \#} \mathrm{P}<0.01$ vs. TNF- $\alpha$ treatment-alone group. TNF- $\alpha$, tumor necrosis factor $\alpha$; Bcl-2, B-cell lymphoma 2; Bax, Bcl-2-associated $\mathrm{X}$ protein; FITC, fluorescein isothiocyanate; PI, propidium iodide.

A

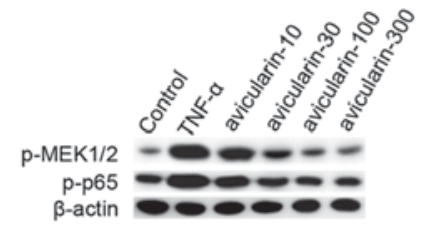

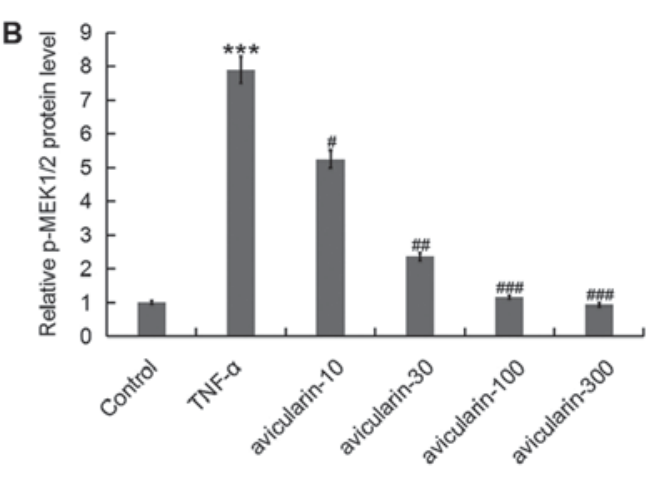

Figure 5. Effect of avicularin on MEK/nuclear factor kappa light-chain-enhancer of activated B-cells pathway in MH7A cells. MH7A cells were pre-treated with various concentrations of avicularin $(10,30,100$ and $300 \mu \mathrm{M})$ for $2 \mathrm{~h}$, then the cells were subjected to treatment with $10 \mathrm{ng} / \mathrm{ml} \mathrm{TNF}-\alpha$ at room temperature for $24 \mathrm{~h}$. The protein level of p-MEK1/2 and p-p65 was measured using (A) western blot analysis, and the data for (B) p-MEK1/2 and (C) p-p65 were analyzed. Data are expressed as the mean \pm standard deviation. ${ }^{* * * *} \mathrm{P}<0.001$ vs. control group; ${ }^{\#} \mathrm{P}<0.05,{ }^{\# \#} \mathrm{P}<0.01$ and ${ }^{\# \# \#} \mathrm{P}<0.001$ vs. TNF- $\alpha$ treatment-alone group. MEK1/2, mitogen-activated protein kinase 1/2; TNF- $\alpha$, tumor necrosis factor $\alpha$; p65, transcription factor 65; p, phosphorylated.

mechanism of avicularin on SFs in RA remains unclear. Therefore, the present study was conducted to explore whether avicularin exerted an effect on RA through regulating SFs.
Firstly, an in vitro model of RA was established by treating the human RA synovial MH7A cell line with $10 \mathrm{ng} / \mathrm{ml} \mathrm{TNF}-\alpha$ for $24 \mathrm{~h}$. It was identified that TNF- $\alpha$ treatment significantly increased the inflammatory response in 
MH7A cells, evidenced by increased expression levels of inflammatory factors including IL-1 $\beta$, IL-6, IL-8, MMP-1 and MMP-13. It was also identified that TNF- $\alpha$ treatment significantly promoted cell viability and inhibited cell apoptosis in MH7A cells. As hypothesized, additional analysis indicated that avicularin administration dose-dependently decreased the levels of IL-1 $\beta$, IL- 6 , IL-8, MMP-1 and MMP-13, inhibited MH7A cell viability and induced cell apoptosis.

iNOS is a major producer of NO and serves an important role in the progression of inflammatory diseases, including RA (31).COX-2, which is involved in the inflammatory response and is increased in inflammation-associated cells following cytokine stimulation during the immune reaction, was revealed to be upregulated during RA development $(31,32)$. Consistent with previous studies $(31,33)$, the present study identified that TNF- $\alpha$ treatment significantly increased the expression levels of iNOS and COX-2 in MH7A cells, and the increased levels of iNOS and COX-2 caused by TNF- $\alpha$ treatment were dose-dependently decreased by avicularin administration. To additionally explore the underlying mechanism of the effect of avicularin on MH7A cells, the MEK-NF- $\mathrm{B}$ pathway, which has been identified to be repressed by avicularin in RAW 264.7 macrophages (17), was investigated. The results suggested that the activation of MEK-NF- $\kappa$ B pathway caused by $\mathrm{TNF}-\alpha$ treatment was prevented by avicularin treatment in a dose-dependent manner.

In summary, to the best of our knowledge, the present study identified for the first time that avicularin inhibited the inflammatory response, prevented cell viability and induced apoptosis in TNF- $\alpha$-treated human RA synovial cells through preventing the activation of the $\mathrm{MEK} / \mathrm{NF}-\kappa \mathrm{B}$ pathway. Therefore, avicularin may serve as a promising therapeutic agent for the treatment of RA. However, this is a preliminary study examining the effect of avicularin on $\mathrm{RA}$; the protective effect of avicularin on RA requires additional study. Compared with other flavonoids, the advantage of using avicularin for RA is largely unclear; future studies are required to compare the effects of avicularin and other flavonoids on RA. In addition, the in vitro model of RA is significantly different from in vivo RA in humans; therefore, additional in vivo experiments and clinical studies are also required to demonstrate the protective effect of avicularin on RA. Future studies conducted by this group will examine these issues in-depth.

\section{Acknowledgements}

Not applicable.

\section{Funding}

The present study was supported by Hangzhou Municipal Science and Technology Commission (grant no. 20150733Q43).

\section{Availability of data and materials}

The analyzed data sets generated during the present study are available from the corresponding author on reasonable request.

\section{Authors' contributions}

WW designed the study. HZ, MZ and XL accessed and analyzed the data. JY collaborated to analysis the data and write the paper. All authors collaborated to interpret results and develop the manuscript.

\section{Ethics and consent to participate}

Not applicable.

\section{Patient consent for publication}

Not applicable.

\section{Competing interests}

The authors declare that they have no competing interests.

\section{References}

1. Smolen JS, Aletaha D and McInnes IB: Rheumatoid arthritis. Lancet 388: 2023-2038, 2016.

2. Challal S, Minichiello E, Boissier MC and Semerano L: Cachexia and adiposity in rheumatoid arthritis. Relevance for disease management and clinical outcomes. Joint Bone Spine 83: 127-133, 2016.

3. Ji L, Geng Y, Zhou W and Zhang Z: A study on relationship among apoptosis rates, number of peripheral $\mathrm{T}$ cell subtypes and disease activity in rheumatoid arthritis. Int J Rheum Dis 19: 167-171, 2016.

4. Symmons DP: Epidemiology of rheumatoid arthritis: Determinants of onset, persistence and outcome. Best Pract Res Clin Rheumatol 16: 707-722, 2002.

5. Sun J, Yan P, Chen Y, Chen Y, Yang J, Xu G, Mao H and Qiu Y: MicroRNA-26b inhibits cell proliferation and cytokine secretion in human RASF cells via the Wnt/GSK-3 $\beta / \beta$-catenin pathway. Diagn Pathol 10: 72, 2015.

6. van der Geest KS, Smigielska-Czepiel K, Park JA, Abdulahad WH, Kim HW, Kroesen BJ, van den Berg A, Boots AM, Lee EB and Brouwer E: SF Treg cells transcribing high levels of Bcl-2 and microRNA-21 demonstrate limited apoptosis in RA. Rheumatology (Oxford) 54: 950-958, 2015.

7. Xu WD, Zhang M, Zhang YJ and Ye DQ: IL-33 in rheumatoid arthritis: Potential role in pathogenesis and therapy. Hum Immunol 74: 1057-1060, 2013

8. Song YJ, Li G, He JH, Guo Y and Yang L: Bioinformatics-based identification of microRNA-regulated and rheumatoid arthritis-associated genes. PLoS One 10: e0137551, 2015.

9. Huber LC, Distler O, Tarner I, Gay RE, Gay S and Pap T: Synovial fbroblasts: Key players in rheumatoid arthritis. Rheumatology (Oxford) 45: 669-675, 2006.

10. Lowin T and Straub RH: Synovial fbroblasts integrate inflammatory and neuroendocrine stimuli to drive rheumatoid arthritis. Expert Rev Clin Immunol 11: 1069-1071, 2015.

11. McInnes IB and Schett G: Pathogenetic insights from the treatment of rheumatoid arthritis. Lancet 389: 2328-2337, 2017.

12. Edhayan G, Ohara RA, Stinson WA, Amin MA, Isozaki T, Ha CM, Haines GK III, Morgan R, Campbell PL, Arbab AS, et al: Inflammatory properties of inhibitor of DNA binding 1 secreted by synovial fibroblasts in rheumatoid arthritis. Arthritis Res Ther 18: 87, 2016.

13. Williams RJ, Spencer JP and Rice-Evans C: Flavonoids: Antioxidants or signalling molecules? Free Radic Biol Med 36: 838-849, 2004.

14. Kim JA,Jung YS, Kim MY, Yang SY,Lee Sand Kim YH: Protective effect of components isolated from Linderaerythrocarpa against oxidative stress-induced apoptosis of H9c2 cardiomyocytes. Phytother Res 25: 1612-1617, 2011.

15. Kim SM, Kang K, Jho EH, Jung YJ, Nho CW, Um BH and Pan CH: Hepatoprotective effect of flavonoid glycosides from lespedeza cuneata against oxidative stress induced by tertbutyl hyperoxide. Phytother Res 25: 1011-1017, 2011. 
16. Guo XF, Liu JP, Ma SQ, Zhang P and Sun WD: Avicularin reversed multidrug-resistance in human gastric cancer through enhancing Bax and BOK expressions. Biomed Pharmacother 103: 67-74, 2018.

17. Vo VA, Lee JW, Chang JE, Kim JY, Kim NH, Lee HJ, Kim SS Chun W and Kwon YS: Avicularin inhibits lipopolysaccharide-induced inflammatory response by suppressing ERK phosphorylation in RAW 264.7 macrophages. Biomol Ther (Seoul) 20: 532-537, 2012.

18. Fujimori $\mathrm{K}$ and Shibano M: Avicularin, a plant flavonoid, suppresses lipid accumulation through repression of $\mathrm{C} / \mathrm{EBP} \alpha$-activated GLUT4-mediated glucose uptake in 3T3-L1 cells. J Agric Food Chem 61: 5139-5147, 2013.

19. Pan F, Zhu L, Lv H and Pei C: Quercetin promotes the apoptosis of fibroblast-like synoviocytes in rheumatoid arthritis by upregulating lncRNA MALAT1. Int J Mol Med 38: 1507-1514, 2016.

20. Javadi F, Ahmadzadeh A, Eghtesadi S, Aryaeian N Zabihiyeganeh M, Rahimi Foroushani A and Jazayeri S: The effect of quercetin on inflammatory factors and clinical symptoms in women with rheumatoid arthritis: A double-blind, randomized controlled trial. J Am Coll Nutr 36: 9-15, 2017.

21. Hong Z, Li J, Biswas S, Jiang CS, Huang Y, Sun T, Niu Y, Yu JQ, Li WQ and Yao Y: Ramosissimin, a new flavonol from tararix ramosissima, induces apoptosis in rheumatoid arthritis fibroblast-like synoviocytes. Pharmazie 73: 169-173, 2018.

22. Hollman PC, de Vries JH, van Leeuwen SD, Mengelers MJ and Katan MB: Absorption of dietary quercetin glycosides and quercetin in healthy ileostomy volunteers. Am J Clin Nutr 62: 1276-1282, 1995.

23. Mo X, Chen J, Wang X, Pan Z, Ke Y, Zhou Z, Xie J, Lv G and Luo X: Krüppel-like factor 4 regulates the expression of inducible nitric oxide synthase induced by TNF- $\alpha$ in human fibroblast-like synoviocyte MH7A cells. Mol Cell Biochem 438: 77-84, 2018.

24. Lee GH, Lee J, Lee JW, Choi WS and Moon EY: B cell activating factor-dependent expression of vascular endothelial growth factor in MH7A human synoviocytes stimulated with tumor necrosis factor- $\alpha$. Int Immunopharmacol 17: 142-147, 2013.
25. Jia Q, Cheng W, Yue Y, Hu Y, Zhang J, Pan X, Xu Z and Zhang P: Cucurbitacin $\mathrm{E}$ inhibits TNF- $\alpha$-induced inflammatory cytokine production in human synoviocyte MH7A cells via suppression of $\mathrm{PI} 3 \mathrm{~K} / \mathrm{Akt} / \mathrm{NF}-\kappa \mathrm{B}$ pathways. Int Immunopharmacol 29: 884-890, 2015.

26. Livak KJ and Schmittgen TD: Analysis of relative gene expression data using real-time quantitative PCR and the 2(-Delta-Delta C(T)) method. Methods 25: 402-408, 2011.

27. Pope RM: Apoptosis as a therapeutic tool in rheumatoid arthritis. Nat Rev Immunol 2: 527-535, 2002.

28. Huang H, Xiao Y, Lin H, Fu D, Zhan Z, Liang L, Yang X, Fan J, Ye Y, Sun L and Xu H: Increased phosphorylation of ezrin/radixin/moesin proteins contributes to proliferation of rheumatoid fibroblast-like synoviocytes. Rheumatology (Oxford) 50: 1045-1053, 2011

29. Gerlag DM and Tak PP: Novel approaches for the treatment of rheumatoid arthritis: Lessons from the evaluation of synovial biomarkers in clinical trials. Best Pract Res Clin Rheumatol 22: 311-323, 2008.

30. Szekanecz Z and Koch AE: Angiogenesis and its targeting in rheumatoid arthritis. Vascul Pharmacol 51: 1-7, 2009.

31. Sultana F and Rasool M: A novel therapeutic approach targeting rheumatoid arthritis by combined administration of morin, a dietary flavanol and non-steroidal anti-inflammatory drug indomethacin with reference to pro-inflammatory cytokines, inflammatory enzymes, RANKL and transcription factors. Chem Biol Interact 230: 58-70, 2015.

32. Orita K, Hiramoto K, Kobayashi H, Ishii M, Sekiyama A and Inoue M: Inducible nitric oxide synthase (inos) and $\alpha$-melanocyte-stimulating hormones of inos origin play important roles in the allergic reactions of atopic dermatitis in mice. Exp Dermatol 20: 911-914, 2011.

33. Yao RB, Zhao ZM, Zhao LJ and Cai H: Sinomenine inhibits the inflammatory responses of human fibroblast-like synoviocytes via the TLR4/MyD88/NF- $\kappa \mathrm{B}$ signaling pathway in rheumatoid arthritis. Pharmazie 72: 355-360, 2017. 